\title{
The Restore4Stroke self-management intervention 'Plan ahead!': rationale and description of the treatment protocol based on proactive action planning
}

Citation for published version (APA):

Tielemans, N. S., Schepers, V. P. M., Visser-Meily, J. M. A., van Erp, J., Eijkenaar, M., \& van Heugten, C. M. (2014). The Restore4Stroke self-management intervention 'Plan ahead!': rationale and description of the treatment protocol based on proactive action planning. Clinical Rehabilitation, 28(6), 530-540. https://doi.org/10.1177/0269215513514460

Document status and date:

Published: 01/06/2014

DOI:

$10.1177 / 0269215513514460$

Document Version:

Publisher's PDF, also known as Version of record

Document license:

Taverne

Please check the document version of this publication:

- A submitted manuscript is the version of the article upon submission and before peer-review. There can be important differences between the submitted version and the official published version of record.

People interested in the research are advised to contact the author for the final version of the publication, or visit the DOI to the publisher's website.

- The final author version and the galley proof are versions of the publication after peer review.

- The final published version features the final layout of the paper including the volume, issue and page numbers.

Link to publication

\footnotetext{
General rights rights.

- You may freely distribute the URL identifying the publication in the public portal. please follow below link for the End User Agreement:

www.umlib.nl/taverne-license

Take down policy

If you believe that this document breaches copyright please contact us at:

repository@maastrichtuniversity.nl

providing details and we will investigate your claim.
}

Copyright and moral rights for the publications made accessible in the public portal are retained by the authors and/or other copyright owners and it is a condition of accessing publications that users recognise and abide by the legal requirements associated with these

- Users may download and print one copy of any publication from the public portal for the purpose of private study or research.

- You may not further distribute the material or use it for any profit-making activity or commercial gain

If the publication is distributed under the terms of Article 25fa of the Dutch Copyright Act, indicated by the "Taverne" license above, 


\section{The Restore4Stroke}

self-management intervention

'Plan ahead!': rationale and

description of the treatment

protocol based on proactive action planning
Clinical Rehabilitation

2014, Vol. 28(6) 530-540

(C) The Author(s) 2014

Reprints and permissions:

sagepub.co.uk/journalsPermissions.nav

DOI: $10.1177 / 0269215513514460$

cre.sagepub.com

@SAGE

\author{
Nienke S Tielemans',2, Vera PM Schepers², \\ Johanna MA Visser-Meily2, Jos van Erp ${ }^{3}$, \\ Mariette Eijkenaar ${ }^{4}$ and Caroline $M$ van Heugten ${ }^{1,5}$
}

This series of articles for rehabilitation in practice aims to cover a knowledge element of the rehabilitation medicine curriculum. Nevertheless they are intended to be of interest to a multidisciplinary audience. The competency addressed in this article is teaching stroke patients and partners proactive action planning in order to enhance their self-management abilities.

\begin{abstract}
Objective: To describe the rationale behind and description of a group-based self-management intervention developed for stroke patients and their partners.

Rationale: Based on the assumption that proactive coping strategies are beneficial for the re-uptake of daily life by stroke patients and partners, we developed a new stroke-specific, group-based selfmanagement intervention based on proactive action planning. A first concept of the treatment protocol was developed based on the proactive coping theory, the Health Action Process Approach model, existing interventions and expert consultations. Further adjustments were based on two pilot studies, including addition of solution-based therapeutic techniques.
\end{abstract}

\footnotetext{
ISchool for Mental Health and Neuroscience, Department of Psychiatry and Neuropsychology, Maastricht University Medical Centre, Maastricht, The Netherlands

${ }^{2}$ Brain Center Rudolf Magnus and Center of Excellence for Rehabilitation Medicine, University Medical Center Utrecht and De Hoogstraat Rehabilitation, Utrecht, The Netherlands

${ }^{3}$ Dutch Heart Foundation, The Hague, The Netherlands ${ }^{4}$ Merem Treatment Centres, Rehabilitation Centre De Trappenberg, Almere, The Netherlands
}

\footnotetext{
${ }^{5}$ Department of Neuropsychology and Psychopharmacology, Faculty of Psychology and Neurosciences, Maastricht University, Maastricht, The Netherlands

Corresponding author:

Caroline van Heugten, Department of Psychiatry and Neuropsychology, Faculty of Health, Medicine and Life Sciences, Maastricht University, PO Box 616, Maastricht, MD 6200, The Netherlands.

Email: c.vanheugten@maastrichtuniversity.nl
} 
Description of the intervention: 'Plan ahead!' is a I0-week group-based self-management intervention, consisting of six 2-hour sessions in the first six weeks and a 2-hour booster session in the 10th week. It is offered in an outpatient setting by two rehabilitation professionals with experience in group counselling and working with stroke patients. It is provided to groups of four stroke patients living at home (stroke $\geq 2$ months ago) and their partners. The main features are (I) proactive action planning as the main constituent, (2) stroke-specific elements and (3) considering partners as full participants.

Discussion: This stroke-specific intervention is expected to increase the use of proactive action planning and thus improve the participation of stroke patients and their partners. It is innovative in its aim to change behaviour patterns of participants directly, teaching participants a general action planning strategy and considering partners as full participants with their own goals and opportunities.

\section{Keywords}

Stroke, family-centred, proactive coping, group intervention

Received: 20 February 2013; accepted: 2 November 2013

\section{Introduction}

Stroke puts heavy demands on patients' self-management abilities, their abilities to manage the medical, physical, emotional and social consequences of stroke and its considerable impact on their daily lives. ${ }^{1}$

Stroke is a chronic (long-term) condition. In other chronic diseases, interventions aimed at enhancing self-management capacities show positive effects on coping, goal achievement, self-efficacy, health-related quality of life and utilization of healthcare services..$^{2-5}$ Several of these interventions are based on the assumption that self-management tasks are similar in different chronic diseases, and that performance of these tasks can be enhanced with a generic programme. ${ }^{1,6}$

However, in case of stroke we believe it is better to adopt a disease-specific approach with tailored levels of self-management tasks. Although it is required to some extent to control or change lifestyle and cardiovascular risk factors, and to manage the medical condition, the greater part of the selfmanagement tasks result from the need for adjustment to the sudden, lasting consequences. ${ }^{7}$ In addition to the possible physical consequences, stroke patients and their partners are confronted with a wide range of non-physical consequences regarding cognitive, emotional, behavioural and social functioning. These consequences can result not only from the emotional processes related to being confronted with a chronic condition, but can also be the direct result of the brain damage itself. Because of the persistent nature of these consequences, adjusting to them is important. ${ }^{8}$ Influential determinants for successful adjustment post stroke are the coping strategies someone adopts., ${ }^{9,10}$ Therefore, self-management interventions aimed at specific coping strategies are expected to be beneficial after stroke.

At the moment, most effective stroke-specific self-management interventions aim to change cognitions about underlying goals, such as increasing self-efficacy and adequate goal setting. ${ }^{11-15}$ In daily life, however, patients fail to pursuit their goals, as they are restrained by unanticipated consequences of stroke. ${ }^{8}$ Several interventions have been proposed to deal with such problems in stroke patients, such as motivational interviewing or problem-solving therapy. ${ }^{16-19}$ However, these interventions have a reactive nature, as they focus on already existing/ identified problems. Proactive coping post stroke involves anticipating potential difficulties and alternative solutions before undertaking an activity, in order to prevent or to prepare oneself for these consequences in advance. ${ }^{20}$ Thus, teaching stroke patients proactive coping strategies is expected to enable them to accomplish more goals and activities successfully, resulting in improved societal participation. In patients newly diagnosed with type 2 diabetes and elderly people, such interventions have already been shown to be effective. ${ }^{21,22}$ We therefore developed a group-based self-management 
intervention called 'Plan ahead!', which to our knowledge is the first stroke-specific self-management intervention teaching proactive coping strategies to stroke patients and partners in order to improve their participation.

This paper describes the theoretical basis and content of the treatment protocol for 'Plan ahead!'. The design of the study evaluating the effectiveness of this intervention is published elsewhere. ${ }^{23}$

\section{Theoretical background}

Our intervention aims to teach participants strategies to plan their intended goals proactively. In daily life, many stroke patients may fail to achieve their goals. ${ }^{8}$ According to the Health Action Process Approach model, goal achievement is the result of a two-phase process. ${ }^{24}$ First, intentions for achieving a particular goal are developed based on levels of risk perception, outcome expectancies and self-efficacy. Subsequently, actual actions are planned, initiated, maintained and adjusted both to reach the goal and to deal with potential barriers. In stroke patients, problems frequently occur during this second phase: patients fail to pursuit their goals, as they are restrained by consequences of stroke. ${ }^{8}$

Proactive coping strategies are expected to enable stroke patients to prevent or prepare themselves for these consequences before undertaking an activity. ${ }^{20}$ According to Aspinwall and Taylor, ${ }^{20}$ proactive coping consists of five interrelated stages: (1) resource collection, (2) noticing potential stressors, (3) initial estimation of the stressor, (4) adoption of the first coping strategies, and (5) evaluation and use of feedback. ${ }^{20}$ We hypothesized that when stroke patients learn to set their goals proactively, they are less constrained by the consequences of stroke as they have already anticipated the potential occurrence of these barriers/requirements and thought about solutions for them. Therefore, it is expected that the impact of stroke on stroke patients' daily lives is reduced when proactive coping strategies are applied.

After a stroke, partners are confronted with their own physical and emotional problems, in addition to their role as family member and caregiver. ${ }^{25}$ Interventions aimed at coping strategies are expected to be beneficial to them as well, which is why we regard partners of stroke patients as full participants in the intervention instead of being in the more usual role as caregiver to the patient. ${ }^{26}$

\section{The intervention 'Plan ahead!'}

\section{Development of the intervention}

In Figure 1 a flowchart depicts the development process of the intervention. The basis for our intervention 'Plan ahead!' is the proactive coping theory, and an existing self-management intervention specifically developed for patients newly diagnosed with type 2 diabetes. ${ }^{21,27,28}$ From this latter programme we adopted the proactive action planning tool and adjusted it for stroke patients.

The initial version of our intervention was developed and reviewed by consultations with several experts (both clinicians and self-management experts), and previous experiences with two other interventions. ${ }^{29-31}$ The development process was finished by testing the intervention in two pilot studies. The intervention group of our latter pilot study also included one patient with an acquired brain injury condition other than stroke. The practical reason behind this was that the intervention had to fit into the fixed schedule of continuous intervention provision of the piloting institute to mixed groups of acquired brain injury patients. This required a quicker recruitment of participants than possible with stroke patients only. After each pilot study, we adjusted the treatment protocol based on our own observations and the feedback reported by participants and rehabilitation medicine professionals.

\section{Participants}

The intervention was developed for stroke patients living at home who experience restrictions in their daily lives. A minimum period of two months is recommended between the stroke and the start of the intervention, as recovery has taken place for a large extent after two months. ${ }^{32}$ Since many of the consequences of stroke are long term, no maximum period after the stroke is indicated. . $^{8,33-36}$ Partners of participating stroke patients are invited to take part in the intervention as well. Patients and 


\section{DEVELOPMENT OF THE TREATMENT}

Theories:

- HAPA-model ${ }^{24}$

Other interventions:

Expert consultations:

- Self-management intervention Beyond

Good Intentions ${ }^{21,27,28}$

$>$ failure in goal pursuit phase

- Proactive coping theory ${ }^{20}$

$>$ proactive action planning tool

$>$ proactive coping beneficial

in preventing this failure

- intervention University Medical Centre

Utrecht ${ }^{29}$

$>$ structure, themes

- Intervention from the Dutch Heart

Foundation for stroke patients ${ }^{30,31}$

$>$ focus on goals/ opportunities, themes

- Researchers

- Healthcare professionals

- psychologist

- occupational therapists

- specialized nurses

- rehabilitation physicians

FIRST CONCEPT OF THE TREATMENT PROTOCOL

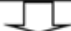

\section{PILOTING}

Pilot study 1: $\quad 3$ stroke patients and 2 partners

Major changes afterwards:

- adding time for sharing experiences at the start of the intervention

- adding a theme (i.e. less visible consequences of stroke)

- providing a small amount of theme-related information as starting point for the discussions

- adding an additional stage to the action planning tool (i.e. defining desired changes)

- allowing non-stroke related goals, choosing one main goal, and allowing global goals

- executing of an evaluation of the action planning during the following sessions only

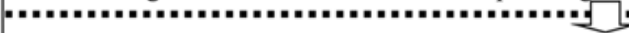

\section{ADJUSTMENT OF TREATMENT PROTOCOL}

Pilot study 2: $\quad 2$ stroke patients, 1 brain tumor patient and 1 partner of a stroke patient

Major change afterwards: asking solution-based questions next to problem-based questions

TREATMENT PROTOCOL VERSION EVALUATED FOR EFFECTIVENESS AND PRESENTED IN THIS ARTICLE

Figure I. Flowchart of the development process of the intervention. 
partners should not be offered the intervention if they (1) have insufficient mental and/or communicative ability to understand and learn from the intervention, and/or (2) are unable or unwilling to function in a group because of behavioural problems. These criteria can be clinically judged, for example, by a rehabilitation physician.

\section{Therapists}

The intervention is offered by two rehabilitation professionals such as occupational therapists, psychologists, social workers or specialized nurses. At least one-year working experience with stroke patients is recommended, as we assume this enables the professionals to provide appropriate support, discuss relevant themes and make realistic estimations of achievable goals of participants. Moreover, some experience in group counselling is recommended, to ensure that the professional knows how to lead group processes and handle interactions between group members.

\section{Stroke-specific elements of the intervention}

Several stroke-specific elements are applied in our intervention. The most important one is the strokespecific version of the proactive action plan tool, which is presented in Table 1. Two examples of participants working with this tool are given in Box 1. It is important to note that action planning by means of this plan is a dynamic process. Participants can return to previous stages at any moment to refine or change the decisions made earlier on.

During the pilot studies, it appeared that participants were used to thinking about problems, barriers and situations in which they fail, but found it hard to think about goals, opportunities and solutions spontaneously. Rehabilitation medicine professionals were able to facilitate proactive action planning by not only asking questions from problem-based perspective, but also from a solutionbased perspective. ${ }^{37}$ Problem-based questions are expected to stimulate discussions about problems and barriers. Examples of problem-based questions are 'What is restraining you?' and 'Can you describe a recent situation in which the problem occurred?'. Solution-based questions facilitate thinking about goals, opportunities and solutions. Examples of solution-based questions are 'What do you want to achieve?' and 'Can you describe a recent situation in which the problem did not occur, although you were expecting it?'. Table 1 schematically presents the perspective rehabilitation medicine professionals should adopt during each stage of proactive-action planning.

Another stroke-specific element is the time provided to discuss stroke-relevant information. During our first pilot study, it appeared to be essential to provide participants some time to discuss their stroke-related experiences, before focusing on future changes related to proactive actionplanning. A small amount of stroke-relevant information functioned as a good starting point for these discussions. Moreover, we expect this information provision facilitates awareness of the condition $^{38}$ as well as proactive action planning. ${ }^{39,40}$ Next to this, we limit the group sizes and split up the group when participants work on their proactive action plan, to enable more individual assistance from a healthcare professional.

\section{Description of the intervention}

The 10-week, group-based intervention consists of six 2-hour sessions in the first six weeks and a 2-hour booster session in the 10th week. All sessions are group sessions. Groups consist of four stroke patients, with potentially their partners. It is provided as an outpatient healthcare service at hospitals and rehabilitation centres in the Netherlands. The main elements of our intervention are presented in Table 2.

The first session starts with providing information about the intervention, after which participants are given some time to get to know each other. Subsequently, participants are asked about their expectations of the intervention. Participants are then asked to write down the most notable changes they have experienced since their stroke or the stroke of their partner and to categorize them as affecting physical functioning, cognition, social relations and/ or activities. Finally, participants are invited to discuss the changes they have experienced.

During the second session, information is provided about less visible consequences of stroke (i.e. cognitive impairments, causes and symptoms 


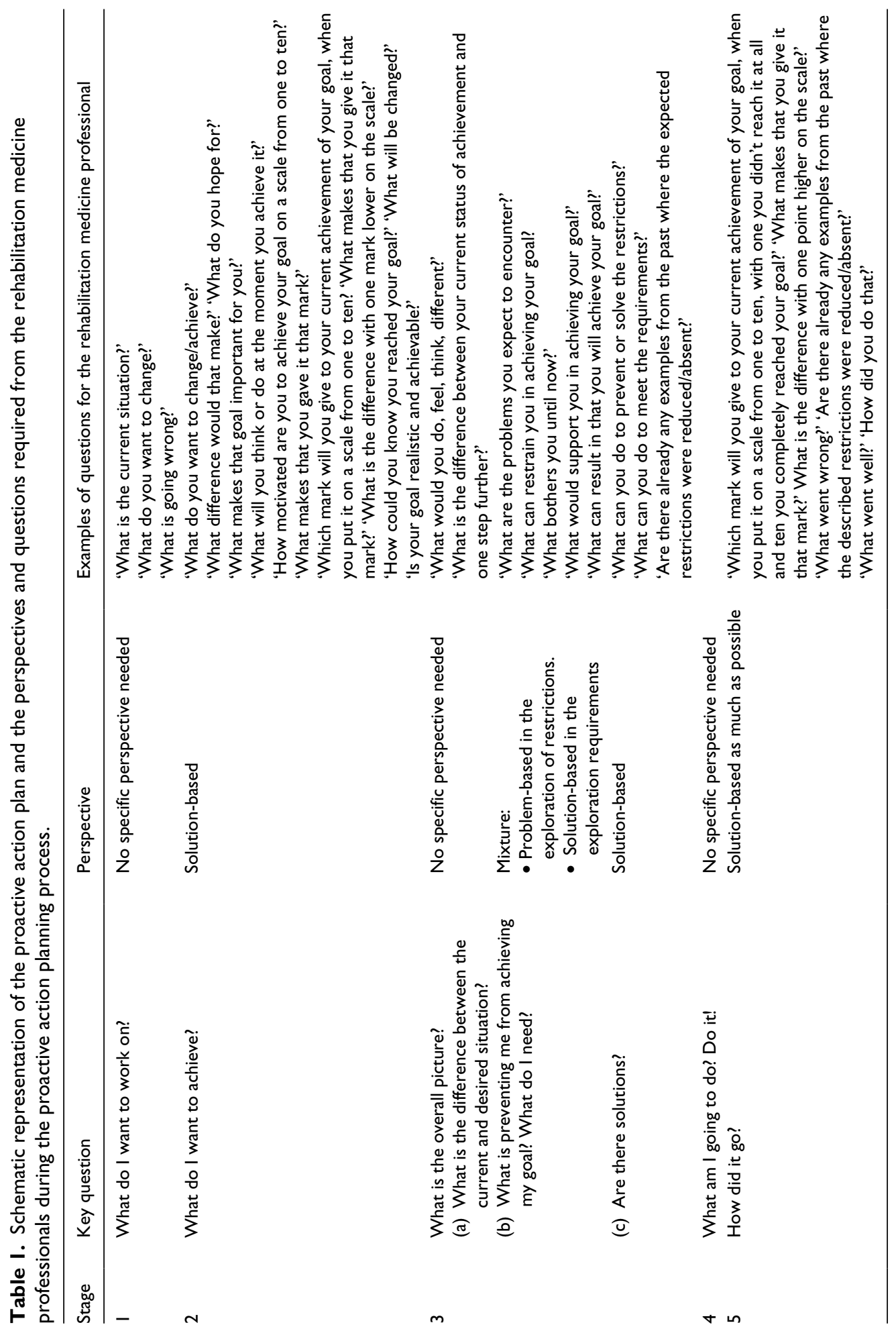


Box I. Characteristics of the intervention.

Case I: KR is a 65-year-old single man who has had a stroke twice. He started the course without any expectations, but immediately knows what he wants to change in his life when asked.

I. What do I want to work on? 'I want to lose the additional weight I gained since stroke'

2. What do I want to achieve?

3. What is the overall picture?

'I want to become fitter and get a more slender figure'

'The difference between the current and desired situations is that I never cook healthy or go by bike to activities'

\section{Barriers/requirements Solutions}

'I am not motivated to cook for 'I invite a friend for dinner' myself exclusively'

'I do not have the energy and 'I prepare the meal in several time to cook an elaborative meal, small steps during the day. Next especially not at the end of the day'

'I haven't tried cycling yet, maybe 'I can ask the physiotherapist to it is still not possible'

'The weather is too bad for cycling'

While KR is thinking about potential barriers, both KR himself and other group members suggest solutions

4. What am I going to do? Do it!

'I am going to eat two healthy meals this week. Later on, I will work on the cycling part of my goal'

5. How did it go?

'I did prepare two healthy meals this week. For one of these meals I invited a friend. I am satisfied about my goal achievement and rate it with a 7 out of 10

In the following weeks, KR tried to persist in cooking a healthy meal twice a week. In the sixth session he decided to work on the cycling part of his goal also. During the booster session he said that he persisted in cooking a healthy meal twice a week, except one week. Next to this, he successfully went cycling with a physiotherapist. One group member suggested he could expand this and promised to send him recipes for healthy meals by mail

Case 2: $\mathrm{AJ}$ is a 68-year-old retired man whose wife has had a stroke.

I. What do I want to work on?

2. What do I want to achieve?

3. What is the overall picture?
'That I am not going out any longer'

'To take up my former life, by going out (with and without my wife) more often'

'The difference between the current and desired situations is that after my wife's stroke, I worry a lot about her'

Barriers/requirements

Solutions

'I am afraid that something will happen to my wife when we are not at home'

'I am afraid that my wife will get something like a stroke again when I am not at home'

'I am afraid that my wife cannot manage a long car ride, and that this will harm her health'
'I trust my wife when she tells me that she is not feeling well'

'To realize that it is not realistic to be with my wife all the time. Moreover, even when I am with her, something like a stroke can happen to her'

'Before we leave, we make an agreement about the several stages in which we divide the car ride'
4. What am I going to do? Do it!

5. How did it go?
'I am going to visit a museum in Amsterdam this week. With my wife I make an agreement about the length of this visit'

'Although I did not visit a museum, I went to my old employer in Amsterdam. I have been there for 2 hours, which means that I left home for 3 hours. I even did not call home. I felt free. I rate this attempt with an 8 out of 10 ' 
Table 2. Characteristics of the intervention.

\begin{tabular}{|c|c|c|c|}
\hline Participants & & \multicolumn{2}{|c|}{$\begin{array}{l}\text { Stroke patients (stroke } \geq 2 \text { months ago) with participation problems, living at home, } \\
\text { and their partners }\end{array}$} \\
\hline Therapists & & \multicolumn{2}{|c|}{$\begin{array}{l}\text { Rehabilitation medicine professionals with at least one year working experience } \\
\text { with patients with stroke. Moreover, some experience in group counselling is } \\
\text { recommended }\end{array}$} \\
\hline \multirow[t]{9}{*}{ Intervention } & Duration & \multicolumn{2}{|c|}{ Ten weeks, with six 2 -hour group sessions and a booster session } \\
\hline & Group size & \multicolumn{2}{|c|}{ 4-8 participants (4 stroke patients and partners) } \\
\hline & Setting & \multicolumn{2}{|c|}{ Outpatient healthcare service of hospitals and rehabilitation centres } \\
\hline & Content & Session & Topic \\
\hline & & $1-2$ & $\begin{array}{l}\text { Time to get to know each other } \\
\text { Information about the consequences of stroke, with } \\
\text { special attention for the less visible consequences } \\
\text { Sharing common problems with peers }\end{array}$ \\
\hline & & 3 & $\begin{array}{l}\text { Formulating goals } \\
\text { Getting acquainted with proactive action planning }\end{array}$ \\
\hline & & $4-6$ & $\begin{array}{l}\text { Provision of theme-related information to improve } \\
\text { understanding of potential barriers/ requirements and } \\
\text { solutions } \\
\text { Integration of theme-related information with proactive } \\
\text { action planning }\end{array}$ \\
\hline & & Booster & $\begin{array}{l}\text { Recapitulating intervention content } \\
\text { Sharing intervention-related experiences }\end{array}$ \\
\hline & Materials & \multicolumn{2}{|c|}{$\begin{array}{l}\text { Manuals and presentations for professionals } \\
\text { Workbooks for participants }\end{array}$} \\
\hline
\end{tabular}

of cognitive problems, recovery, and advices to deal with these consequences). Participants are asked to supplement the information by their own experiences, to clarify the information further and facilitate recognition. At the end of this session, participants are asked to think about a (realistic) change they would desire.

During the third session, the proactive action plan tool is introduced, and illustrated by means of an example. Participants are asked to specify their desired change on the basis of the proactive action plan tool. Non-stroke-related goals are allowed, in view of the importance of autonomous motivation. ${ }^{41}$ The participants are asked to carry out the first step towards reaching their goal in the following week. If participants do not manage to complete their proactive action plan during the session, they are asked to complete their proactive action plan on their own at home.

Sessions 4, 5 and 6 start with an evaluation of the participants' progress towards their goals. After this evaluation, the sessions continue with standardized information provision and sharing common problems related to the theme of (1) (negative) emotional consequences (session 4), (2) social support and relations (session 5) and (3) participation in society (session 6). ${ }^{42,43}$ The sessions are continued by encouraging participants to identify themerelated barriers and conditions that might be relevant to their proactive action plan. The group is then split up into two subgroups, in which participants can work out their individual proactive action plans with more individual assistance from a professional. As group dynamics vary between groups, therapists themselves had to decide how they split up the groups. Participants are allowed to work on the same goal through all sessions, as participants experienced changing their goal every week as frustrating during the pilot study. If ready, participants are asked to implement the formulated concrete actions for the following week in their daily lives.

A booster session takes place in the 10th week. This session starts with an evaluation of the progress made in achieving the goal and continues with a recapitulation of the proactive action plan. This is 
followed by a discussion of the expectations of the intervention at the first session, overall progress made by participants and course-related experiences, and future implementation of what they have learned.

\section{Materials}

Participants receive a workbook containing all the information provided during the intervention. If necessary, participants can contact the therapist providing the intervention for advice during the week. For rehabilitation medicine professionals a manual and PowerPoint presentation are available. These materials are available on request from the authors.

\section{Discussion}

In comparison to other stroke-specific self-management interventions, the 'Plan ahead!' self-management intervention for stroke patients and partners aims to change behaviour patterns directly, instead of changing underlying cognitions. ${ }^{11-15}$ Next to this, it distinguishes itself in its theoretical basis of the proactive coping theory. ${ }^{44}$ Furthermore, our intervention differs from most other stroke-specific self-management interventions in the status of full participation given to partners. ${ }^{44}$ Our intervention sets itself apart from more general rehabilitation practice in teaching a general proactive action planning strategy, rather than achieving a particular goal. ${ }^{45}$ Moreover, instead of focusing on problems, the basis of our intervention is shaped by the participants' own goals and opportunities. ${ }^{16-19}$

A strength of the intervention is that during its development, elements were already taken into account that are required for the generalization of the proactive action planning strategies to daily life, such as homework assignments and patient-centred goal setting, inventory barriers and facilitators in different life domains and with examples of other participants, and adding a booster session to our intervention. ${ }^{46,47}$

A limitation is that we were not able to specify the criteria for appropriate timing of our intervention in further detail. Patients differ in their psychosocial adjustment trajectories, as result of differences in awareness of the condition and its consequences, as well as in their ability to accept the condition.
Therefore, differences might result in patients' needs for interventions and their timing., ${ }^{7,48}$ Further research is needed to investigate when provision of an intervention such as ours is appropriate.

The intervention was developed by integrating a theoretical framework with interventions that have proved effective $20,21,24,27-31$ as well as our own observations, experiences and feedback from rehabilitation medicine professionals, stroke patients and their partners. The next step will be to examine the clinical effectiveness and cost-effectiveness of this intervention. The Restore4Stroke self-management project is currently investigating the clinical effectiveness of this self-management intervention in a multicentre randomized controlled trial with a one-year follow-up period, ${ }^{23}$ in which the intervention is compared with a education intervention which is also given as group therapy to patients and partners. The cost-effectiveness of the study is being investigated in the $€$-Restore4Stroke study. ${ }^{49}$

\section{Clinical messages}

- Stroke imposes great demands on patients' and partners' abilities to manage lasting consequences. Self-management interventions aimed at coping strategies are expected to be beneficial.

- A new self-management intervention is described aimed at teaching stroke patients and partners proactive action planning.

- Partners are invited as full participants.

\section{Author contributions}

$\mathrm{JV}$ and $\mathrm{CH}$ developed the idea and procured funding for this work. NT, VS, JV, JE and CH developed the intervention. All authors reviewed the manuscript and approved the final version.

\section{Acknowledgements}

We would like to thank all patients, partners and healthcare professionals for their contribution to the development of the intervention. Special thanks go to Jacqueline Sibbel, Joke Hoekstra, Haike van Stralen and Rinske Maathuis for their valuable contributions. 


\section{Conflict of interest}

The authors declare that there is no conflict of interest.

\section{Funding}

This work was supported by the Dutch VSBFonds (no. 89000004); and the Dutch Heart Foundation.

\section{References}

1. Barlow J, Wright C, Sheasby J, Turner A and Hainsworth J. Self-management approaches for people with chronic conditions: a review. Patient Educ Couns 2002; 48: 177-187.

2. Barlow JH, Turner AP and Wright CC. A randomized controlled study of the Arthritis Self-Management Programme in the UK. Health Educ Res 2000; 15: 665680 .

3. Thoolen B, de Ridder D, Bensing J, Gorter K and Rutten G. Beyond Good Intentions: the development and evaluation of a proactive self-management course for patients recently diagnosed with type 2 diabetes. Health Educ Res 2008; 23: 53-61.

4. Bourbeau J, Julien M, Maltais F, et al. Reduction of hospital utilization in patients with chronic obstructive pulmonary disease: a disease-specific self-management intervention. Arch Intern Med 2003; 163: 585-591.

5. Newman S, Steed L and Mulligan K. Self-management interventions for chronic illness. Lancet 2004; 364: 1523 1537.

6. WagnerEH,Austin BT, Davis C, Hindmarsh M, Schaefer J and Bonomi A. Improving chronic illness care: translating evidence into action. Health Aff (Millwood). 2001; 20: 64-78.

7. Jones F, Riazi A and Norris M. Self-management after stroke: Time for some more questions? Disabil Rehabil 2012; 35: 257-264.

8. Carlsson GE, Moller A and Blomstrand C. A qualitative study of the consequences of 'hidden dysfunctions' one year after a mild stroke in persons $<75$ years. Disabil Rehabil 2004; 26: 1373-1380.

9. Darlington AS, Dippel DW, Ribbers GM, Van Balen R, Passchier $\mathrm{J}$ and Busschbach JJ. A prospective study on coping strategies and quality of life in patients after stroke, assessing prognostic relationships and estimates of costeffectiveness. $J$ Rehabil Med 2009; 41: 237-241.

10. Wolters G, Stapert S, Brands I and Van Heugten C. Coping styles in relation to cognitive rehabilitation and quality of life after brain injury. Neuropsychol Rehabil. 2010; 20: 587-600.

11. Johnston M, Bonetti D, Joice S, et al. Recovery from disability after stroke as a target for a behavioural intervention: results of a randomized controlled trial. Disabil Rehabil 2007; 29: 1117-1127.

12. Kendall E, Catalano T, Kuipers P, Posner N, Buys N and Charker J. Recovery following stroke: the role of selfmanagement education. Soc Sci Med 2007; 64: 735-746.
13. Huijbregts MP, Myers AM, Streiner D and Teasell R. Implementation, process, and preliminary outcome evaluation of two community programs for persons with stroke and their care partners. Top Stroke Rehabil 2008; 15: 503-520.

14. Jones F, Mandy A and Partridge C. Changing self-efficacy in individuals following a first time stroke: preliminary study of a novel self-management intervention. Clin Rehabil 2009; 23: 522-533.

15. Cadilhac DA, Hoffmann S, Kilkenny M, et al. A phase II multicentered, single-blind, randomized, controlled trial of the stroke self-management program. Stroke 2011; 42: 1673-1679.

16. Hegel MT, Dietrich AJ, Seville JL and Jordan CB. Training residents in problem-solving treatment of depression: A pilot feasibility and impact study. Fam Med 2004; 36: 204-208.

17. Lundahl B, Moleni T, Burke BL, et al. Motivational interviewing in medical care settings: a systematic review and meta-analysis of randomized controlled trials. Patient Educ Couns 2013; 93: 157-168.

18. Robinson RG, Jorge RE, Moser DJ, et al. Escitalopram and problem-solving therapy for prevention of poststroke depression: a randomized controlled trial. JAMA 2008; 299: 2391-2400.

19. Watkins CL, Wathan JV, Leathley MJ, et al. The 12-month effects of early motivational interviewing after acute stroke: a randomized controlled trial. Stroke 2011; 42: 1956-1961.

20. Aspinwall LG and Taylor SE. A stitch in time: self-regulation and proactive coping. Psychol Bull 1997; 121: 417-436.

21. Thoolen BJ, de Ridder D, Bensing J, Gorter K and Rutten G. Beyond good intentions: The role of proactive coping in achieving sustained behavioural change in the context of diabetes management. Psychol Health 2009; 24: 237-254.

22. Bode C, de Ridder DT, Kuijer RG and Bensing JM. Effects of an intervention promoting proactive coping competencies in middle and late adulthood. Gerontologist 2007; 47: 42-51.

23. Tielemans NS, Visser-Meily JMA, Schepers VPM, Post MWM, Wade DT and Van Heugten CM. Study protocol of the Restore4Stroke self-management study: A multicenter randomized controlled trial in stroke patients and their partners. Int J Stroke. Epub ahead of print 22 Oct 2013. DOI: 10.1111/ijs.12127.

24. Schwarzer R, Lippke S and Luszczynska A. Mechanisms of health behavior change in persons with chronic illness or disability: the Health Action Process Approach (HAPA). Rehabil Psychol 2011; 56: 161-170.

25. Visser-Meily A, Post M, Gorter JW, Berlekom SB, Van Den Bos T and Lindeman E. Rehabilitation of stroke patients needs a family-centred approach. Disabil Rehabil 2006; 28: 1557-1561.

26. Visser-Meily A, Post M, Van de Port I, Maas C, Forstberg-Warleby G and Lindeman E. Psychological 
functioning of spouses of patients with stroke from initial inpatient rehabilitation to 3 years poststroke: Course and relation with coping strategies. Stroke 2009; 40: 1399-1404.

27. Thoolen B, De Ridder D, Bensing J and Rutten G. Geen woorden maar daden: Handleiding voor verpleegkundigen. Utrecht: Universiteit Utrecht, 2004.

28. Thoolen B, De Ridder D, Bensing J and Rutten G. Geen woorden maar daden: Werkboek. Utrecht: Universiteit Utrecht, 2004.

29. Sibbel J, Visser-Meily A, Hoekstra J, Ruiter N and Post M. Groepsgewijze psycho-educatie voor mensen met licht hersenletsel: Beschrijving van deelnemers en evaluatie. Wetenschapp Tijdschr Ergother 2008; 2: 2-6.

30. Van Erp J and Schipper K. Aandacht voor draagkracht omgaan met CVA: Een nazorgcursus voor patiënten met CVA en partners. Den Haag: De Nederlandse Hartstichting, 2010.

31. Schipper K, Kessels T and Van Erp J. Aandacht voor draagkracht: Omgaan met niet-aangeboren hersenletsel. Een nazorginterventie voor getroffenen en naasten. Psychol Gezondh 2010: 177-182.

32. Langhorne P, Bernhardt J and Kwakkel G. Stroke rehabilitation. Lancet 2011 ; 377; 1693-1702.

33. Duncan PW, Samsa GP, Weinberger M, et al. Health status of individuals with mild stroke. Stroke 1997; 28: 740-745.

34. Muren MA, Hutler M and Hooper J. Functional capacity and health-related quality of life in individuals post stroke. Top Stroke Rehabil. 2008; 15: 51-58.

35. Planton M,Peiffer S, Albucher JF, etal. Neuropsychological outcome after a first symptomatic ischaemic stroke with 'good recovery'. Eur J Neurol 2012; 19: 212-219.

36. Green TL and King KM. Functional and psychosocial outcomes 1 year after mild stroke. J Stroke Cerebrovasc Dis 2010; 19: 10-16.

37. Berg IK and De Jong P. De kracht van oplossingen: Handwijzer voor oplossingsgerichte gesprekstherapie. Amsterdam: Pearson Assessment and Information, 2004.
38. Lucas SE and Fleming JM. Interventions for improving self-awareness following acquired brain injury. Austr Occup Ther J 2005; 52: 160-170.

39. Leach E, Cornwell P, Fleming J and Haines T. Patient centered goal-setting in a subacute rehabilitation setting. Disabil Rehabil. 2010; 32: 159-172.

40. Sugavanam T, Mead G, Bulley C, Donaghy M and Van Wijck F. The effects and experiences of goal setting in stroke rehabilitation - a systematic review. Disabil Rehabil 2013; 35: 177-190.

41. Koestner R, Otis N, Powers TA, Pelletier L and Gagnon $\mathrm{H}$. Autonomous motivation, controlled motivation, and goal progress. J Pers 2008; 76: 1201-1230.

42. Lynch EB, Butt Z, Heinemann A, et al. A qualitative study of quality of life after stroke: the importance of social relationships. J Rehabil Med. 2008; 40: 518-523.

43. Rochette A, Desrosiers J, Bravo G, St-Cyr-Tribble D and Bourget A. Changes in participation after a mild stroke: quantitative and qualitative perspectives. Top Stroke Rehabil 2007; 14: 59-68.

44. Lennon S, McKenna S and Jones F. Self-management programmes for people post stroke: a systematic review. Clin Rehabil 2013; 27: 867-878.

45. Wade DT. Goal setting in rehabilitation: an overview of what, why and how. Clin Rehabil 2009; 23: 291-295.

46. Geusgens CA, Winkens I, Van Heugten CM, Jolles J and Van den Heuvel WJ. Occurrence and measurement of transfer in cognitive rehabilitation: a critical review. $J$ Rehabil Med 2007; 39: 425-439.

47. Fleig L, Pomp S, Schwarzer R and Lippke S. Promoting exercise maintenance: How interventions with booster sessions improve long-term rehabilitation outcomes. Rehabil Psychol. Epub ahead of print 16 Sept 2013. DOI: 10.1037/a0033885.

48. White JH, Magin P, Attia J, Sturm J, Carter G and Pollack M. Trajectories of psychological distress after stroke. Ann Fam Med 2012; 10: 435-442.

49. Van Eeden M, Van Heugten CM and Evers SM. The economic impact of stroke in The Netherlands: the euroRestore4Stroke study. BMC Public Health 2012; 12: 122. 